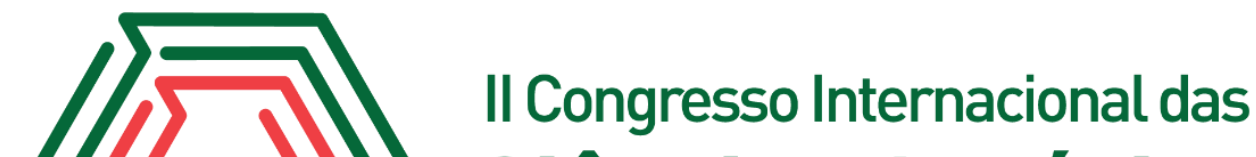 Ciências Agrárias COINTER - PDVAgro 2017
}

\section{CARACTERIZAÇÃO FÍSICA DE LINGUIÇA DE ATUM UTILIZANDO INULINA}

\author{
Apresentação: Pôster
}

Andréia Amanda Bezerra Jácome ${ }^{1}$; Lucas de Oliveira Soares Rebouças²; Julianna Paula do Vale Figueiredo $^{3}$; Vanessa Clarisse Fernandes Alves ${ }^{4}$; Jean Berg Alves da Silva ${ }^{5}$

\section{Introdução}

O atum é uma excelente fonte de proteínas de alto valor biológico, vitaminas e minerais e possui uma baixa concentração em gorduras saturadas e uma elevada concentração de gorduras poliinsaturadas. Estes ácidos gordos insaturados, como o ômega 3, são nutrientes que fazem baixar os níveis de colesterol plasmático, prevenindo o aparecimento de doenças cardiovasculares, podem ajudar a baixar a pressão sanguínea e ainda possuem propriedades anti-inflamatórias (VALA, 2016).

O Brasil apresenta um dos mais baixos índices de consumo de pescado. Este fato se explica, não só por problemas na distribuição e comercialização, como também muitas vezes pela falta do hábito de consumo, gerado em parte pela ausência de praticidade no preparo e falta de diversificação dos produtos assim como a inovação dos mesmos (CARVALHO et al., 2012).

Os peixes podem ser submetidos a uma série de processamentos diferentes, o que permite a obtenção de uma ampla gama de gostos e apresentações, o que torna esta matéria-prima uma das mais versáteis “commodities” alimentícias (FAO, 2007). Um exemplo de diversificação de produtos a base de pescado é o desenvolvimento de embutidos.

O objetivo desse trabalho foi ver a viabilidade da produção de um embutido do tipo linguiça, usando o atum como matéria-prima e substituindo a gordura animal (toucinho) por inulina, e avaliar a as características físicas desse produto.

\footnotetext{
${ }^{1}$ Pós-graduação em Produção Animal, Universidade Federal Rural do Semi-Árido, amandabjacome@gmail.com

2 Pós-graduação em Ciência Animal, Universidade Federal Rural do Semi-Árido,lucaslosr@gmail.com

${ }^{3}$ Pós-graduação em Ciência Animal, Universidade Federal Rural do Semi-Árido, juliannafigueiredo@hotmail.com

${ }^{4}$ Pós-graduação em Produção Animal, Universidade Federal Rural do Semi-Árido, vanessaclaricefa@gmail.com

${ }^{5}$ Doutorado, Universidade Federal Rural do Semi-Árido, jeanberg@ufersa.edu.br
} 


\section{Fundamentação Teórica}

O pescado é um alimento importante na dieta de vários grupos populacionais, pois além de ser uma fonte de proteína de excelente qualidade nutricional, ainda é rico em ácidos graxos poliinsaturados (principalmente os ômegas), que trazem diversos benefícios a saúde humana (RAMOS FILHO et al., 2008).

A indústria do pescado tem sofrido muitas mudanças nos últimos anos, principalmente devido às preferências dos consumidores, disponibilidade de matéria-prima, novos produtos vindos do mercado internacional e as exigências de segurança alimentar reguladas pela legislação nacional e internacional (GONÇALVES, 2011).

O peixe é um produto perecível, que começa a perder qualidade desde o momento de sua captura devido a fatores microbiológicos, físicos e químicos (SANTOS, 2008). Entre os atributos de qualidade física que são mais importantes para o mercado consumidor estão: cor, capacidade de retenção de água, maciez e suculência (ABULARACH et al., 1998).

O RIISPOA define "linguiça" como sendo um produto cárneo obtido de carnes cominuídas das diferentes espécies de animais, condimentados, adicionado ou não de ingredientes, embutido em envoltório natural ou artificial, sendo submetido a processo tecnológico específico (BRASIL, 2017).

O incremento do valor nutricional produtos cárneos pode ser obtido através do da reformulação dos produtos, adicionando ingredientes com propriedades funcionais, como a inulina, que é uma fibra alimentar com propriedades prebióticas (ZHANG et al., 2010; ROBERFROID, 2007).

\section{Metodologia}

O trabalho realizado trata-se de uma pesquisa qualitativa, experimental. De início, foram elaboradas três formulações diferentes para linguiça utilizando atum como matéria-prima, sendo a primeira (LA) o controle, utilizando apenas atum na sua elaboração, a segunda (LAT) com toucinho, e a terceira (LAI) com inulina, substituindo o toucinho. Os demais ingredientes foram sal, pimenta do reino, orégano e alho, todos com a mesma proporção. O processamento da linguiça foi realizado no Laboratório de Análises Instrumentais e Sensoriais (LANIS), seguindo o fluxograma abaixo, em seguida as amostras foram congeladas a $-4^{\circ} \mathrm{C}$ durante 15 dias. 
Figura 1.

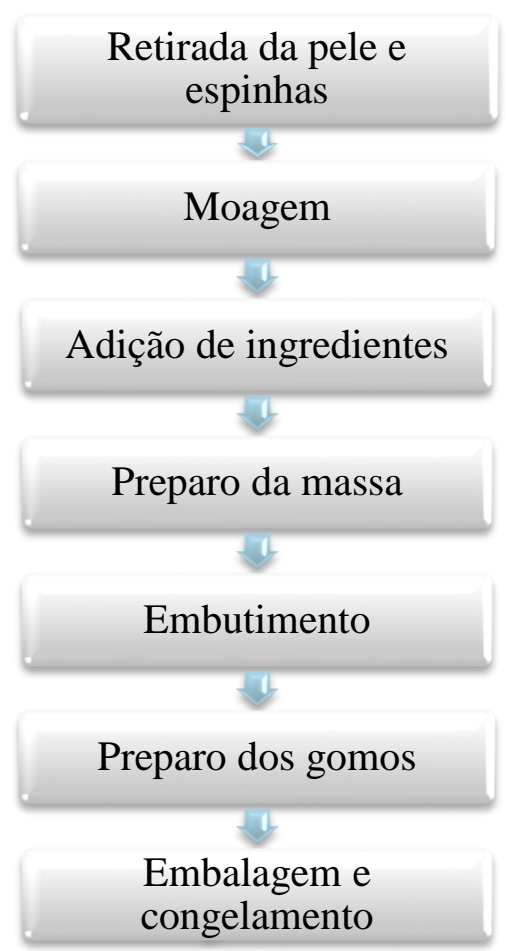

Fluxograma das etapas do processamento da linguiça de atum. Fonte: Própria.

Após o período de congelamento, foram determinados os parâmetros de pH (AOAC 2005), cor, utilizando as coordenadas $\mathrm{L}^{*}, \mathrm{a}^{*}$ e b* (YUAN et al., 2016), capacidade de retenção de água (HAMM, 1960) e perda de peso por cocção (WARRIS, 2003).

\section{Resultados e Discussões}

Os resultados obtidos nas análises físicas das três formulações de linguiça de atum estão expressos na tabela abaixo. 
Tabela 1: Análise física de diferentes formulações de lingüiça de atum, 2017. Fonte: Própria

\begin{tabular}{ccccc}
\hline Parâmetros & LA & LAT & LAI & CV (\%) \\
\hline $\mathrm{pH}$ & $5,30 \mathrm{c}$ & $5,58 \mathrm{a}$ & $5,44 \mathrm{~b}$ & 0,31 \\
$L^{*}$ & $66,49 \mathrm{~b}$ & $68,97 \mathrm{a}$ & $69,14 \mathrm{a}$ & 0,71 \\
$a^{*}$ & $2,10 \mathrm{a}$ & $1,97 \mathrm{a}$ & $1,92 \mathrm{a}$ & 9,84 \\
$b^{*}$ & $6,52 \mathrm{a}$ & $7,46 \mathrm{a}$ & $7,64 \mathrm{a}$ & 6,39 \\
CRA $(\%)$ & $89,02 \mathrm{a}$ & $71,37 \mathrm{~b}$ & $68,24 \mathrm{~b}$ & 9,56 \\
PPC (\%) & $11,71 \mathrm{~b}$ & $9,27 \mathrm{~b}$ & $17,28 \mathrm{a}$ & 3,51 \\
\hline
\end{tabular}

Médias seguidas de letras iguais, em cada linha, não diferiram ao nível de 5\% de significância.

Houve diferença estatística nos valores de $\mathrm{pH}$ das três formulações, sendo LAT a que apresentou pH mais alto. Ao analisar o $\mathrm{pH}$ em linguiça de tilápia, o pH mínimo encontrado foi de 5,81 (MARQUES et al,, 2012). Algumas espécies de peixe, como o atum, apresentam valores de $\mathrm{pH}$ mais baixos (entre 5,4 e 5,6), o que pode explicar o fato de produtos fabricados a base desse peixe apresentarem pH baixo (FAO, 1995; RODRIGUES et al., 2012).

Quanto à cor, nos valores de $L^{*}$ (luminosidade) apenas LA diferiu, apresentando valor mais baixo que as demais, já os valores de $a^{*}$ (teor de vermelho) e $b^{*}$ (teor de amarelo) não diferiram. Foi observado que a linguiça ficou mais escura depois do período de congelamento. De acordo com MENEGAS 2013, a inulina possui capacidade de reflexão de luz semelhante à gordura, não afetando a luminosidade, o que corrobora com os dados obtidos em nosso trabalho, visto que não houve diferença entre esses valores em LAT e LAI.

A capacidade de retenção de água (CRA) diferiu apenas em LA, chegando a 89,02\%. Já a perda de peso por cocção (PPC) diferiu em LAI, com 17,28\%. Os valores de PPC encontrados no nosso trabalho foram inferiores aos que SLEDER, 2015 encontrou para linguiça de tambaqui com diferentes percentuais de gordura. Valores altos de PPC resultam em prejuízo, tanto para a indústria quando para o consumidor. Estudos comprovam que a CRA da carne é inversamente proporcional aos valores de PPC, o que corrobora com os dados encontrados nas análises (SLEDER, 2015).

\section{Conclusões}

É possível a elaboração de um embutido do tipo linguiça a base de atum utilizando inulina como substituto ao toucinho, desenvolvendo um produto mais saudável e aumentando a gama de produtos a base de pescado. Houve diferença estatística entre os tratamentos para a maioria dos 
parâmetros avaliados, sendo o pH o parâmetro com maior diferença.

\section{Referências}

ABUlARACH, M.L.S., ROCHA, C.E., FELÍCIO, P.E. Características de Qualidade do Contrafilé (m. L. dorsi) de Touros Jovens da Raça Nelore. Ciênc. Tecnol. Aliment. 18 (2): 205-210, 1998.

BRASIL. Ministério da Agricultura, Pecuária e Abastecimento. Novo Regulamento da Inspeção Industrial e Sanitária de Produtos de Origem Animal - RIISPOA. Brasília, 2017.

FAO - Food and Agricultural Organization of the United Nations. The state of world fisheries and aquaculture 2006 (SOFIA).Rome: FAO, 2007. 180p.

FOOD AND AGRICULTURE ORGANIZATION - FAO. Quality and quality changes in fresh fish. Roma, 1995.

GONÇALVES, A. A. Tecnologia do pescado: ciência, tecnologia, inovação e legislação. São Paulo. Editora Atheneu. 608 p. 2011.

CARVAlHO, Í. R. C. de.; LiMA, V. C.; COELHO, M. C. S. C.; CAMPOS, R. M. L. de.; COELHO, M. I. de S. Avaliação sensorial de linguiças de peixes. IV Encontro Nacional dos Núcleos de Pesquisa Aplicada em Pesca e Aquicultura. Dezembro de 2012.

MARQUES, L. F. et al. Avaliação da qualidade de linguiça de Tilápia do Nilo (Oreochromis niloticus) Revista Semiárido De Visu, v.2, n.1, p.3-10, 2012.

MENEGAS, L. Z.; PIMENTEL, T. C.; GARCIA, S.; PRUDENCIO, S. H. Dry-fermented chicken sausage produced with inulin and corn oil: Physicochemical, microbiological, and textural characteristics and acceptability during storage. Meat Science, v. 93, p. 501 - 506, 2013.

ROBERFROID, M. B. Prebiotics: the concept revisited. Journal of Nutrition, v. 37, p. 830-837, 2007.

RODRIGUES, B. L. et al. Qualidade físico-química do pescado utilizado na elaboração de sushis e sashimis de atum e salmão comercializados no município do Rio de Janeiro, Brasil. Semina: Ciências Agrárias, Londrina, v. 33, n. 5, p. 1847-1854, set./out. 2012

RAMOS FILHO, M. M. et al. Perfil lipídico de quatro espécies de peixes da região pantaneira de Mato Grosso do Sul. Ciência e Tecnologia de Alimentos, Campinas, v. 2, n. 28, p. 361-365, abr./jun. 2008.

SANTOS, J. M. S. Filetes de Pregado (Psetta máxima) embalados em atmosfera modificada: avaliação da qualidade física, química e microbiológica. Dissertação apresentada para obtenção do grau de Mestre em Controle de Qualidade pela Universidade do Porto. Porto, 2008. Disponível em https://repositorio-aberto.up.pt/bitstream/10216/22595/2/Joana\%20SantosDissertao.pdf acesso em 04 de outubro de 2017. 
SLEDER, F. Desenvolvimento e caracterização de linguiça frescal de Tambaqui (Colossoma macropomum). Dissertação apresentada para obtenção do título de mestre em Ciência Animal pela Universidade Federal de Mato Grosso (UFMG). Cuiabá, 2015.

VALA, M. O. Aplicação de revestimentos edíveis à base de subprodutos da indústria do pescado na preservação de atum fresco. Dissertação para obtenção do Grau de Mestre em Gestão da Qualidade e Segurança Alimentar pela IPL, Peniche-Portugal, 2016. Disponivel em https://iconline.ipleiria.pt/bitstream/10400.8/2281/1/tese_Milene_Vala.pdf acesso em 07 de junho de 2017.

ZHANG, W.; XIAO, S.; SAMARAWEERA, H.; LEE, E. J.; AHN, D. U. Improving functional value of meat products. Meat Science, v. 86, p.15-31, 2010. 